\title{
Understanding long-term post-fire regeneration of a fire-resistant pine species
}

\author{
Javier Méndez ${ }^{1}$ - Gustavo Morales ${ }^{1} \cdot$ Lea de Nascimento $^{1} \cdot$ Rüdiger Otto $^{1}$. \\ Antonio Gallardo $^{2} \cdot$ José María Fernández-Palacios $^{1}$
}

Received: 20 May 2014 / Accepted: 26 March 2015 /Published online: 15 April 2015

(C) INRA and Springer-Verlag France 2015

\begin{abstract}
- Key message The long-term effect of forest fires in the regeneration of Pinus canariensis was studied. Forest fires had little long-term effects on seed production, seedling germination and seedling mortality. The characteristics of different forest stands across the island had influence in some of the regeneration parameters studied.
\end{abstract}

\section{Handling Editor: Eric Rigolot}

Contribution of the co-authors Javier Méndez, Antonio Gallardo and José María Fernández-Palacios designed this study. Javier Méndez, Gustavo Morales, Lea de Nascimento and Rüdiger Otto did the fieldwork. Javier Méndez, Lea de Nascimento and José María Fernández-Palacios performed statistical analysis. Javier Mendez was the principal drafter of the manuscript with the help of the other authors.

Javier Méndez

jmendezh@ull.es

Gustavo Morales

gmorales@ull.es

Lea de Nascimento

leadenas@ull.es

Rüdiger Otto

rudiotto@ull.es

Antonio Gallardo

agallardo@upo.es

José María Fernández-Palacios

jmferpal@ull.es

1 Island Ecology and Biogeography Group, Instituto Universitario de Enfermedades Tropicales y Salud Pública de Canarias (IUETSPC), University of La Laguna, La Laguna 38206, La Laguna (Tenerife), Spain

2 Department of Physics, Chemical and Natural Systems, Universidad Pablo de Olavide, 41013 Seville, Spain
- Context Despite the importance of forest regeneration dynamics after wildfires, little is known about its long-term evolution after a fire.

- Aims We tested the effect of fire on the long-term regeneration dynamics of $P$. canariensis.

- Method In a forest fire chronosequence of five fire ages (time elapsed since the last fire) plus an unburned stand, we monitored seed production, seedling germination and mortality during 2 years.

- Results We detected significant differences among forest stands in seed production, seedling density and mortality but not in germination and turnover. These differences were unrelated to fire age. Seed production was conditioned by the number of large adults and elevation, germination by diameter at breast height (DBH) and soil nitrogen content and mortality by DBH.

- Conclusion We detected no long-term effect of fire on the regeneration of $P$. canariensis in natural pine forest; however, during the first years after fire, modification of nitrogen availability in soil can reduce germination. Stand conditions in natural pine forests appear to mainly control regeneration dynamics. The regeneration strategies and fire-resistance traits of this species have ensured its persistence in the long term.

Keywords Forest · Fire · Pinus canariensis .

Chronosequence $\cdot$ Regeneration $\cdot$ PERMANOVA

\section{Introduction}

Forest fires are one of the most common disturbances in Mediterranean-type ecosystems and the viability of these burned ecosystems is conditioned by species' capacity to ensure their continuity in the ecosystem (Camia et al. 2008). Species survival is also influenced by heterogeneous stand 
conditions produced by fire, i.e. changes in light and humidity conditions or in nutrient availability (Eshel et al. 2000; Catovsky and Bazzaz 2002). Early post-fire and subsequent cohorts would, therefore, face different environmental conditions resulting in diverse effects on the main regeneration processes: seed release, germination and mortality rates.

Most Mediterranean pine species can resist fire, but their degree of resistance (the fire intensity they can tolerate) is variable (Fernandes et al. 2008). Pine strategies to cope with fire depend on either species persistence (by sexual reproduction) or individual survival (Keeley 2012). Obligate seeders, like Pinus halepensis Mill., survive due to serotinous cones that store seeds in aerial banks and then release them only or mostly after fire, producing an immediate post-fire seedling cohort, whose recruitment gives rise to a new population (Keeley 2012). Species without serotinous cones living in fire-prone environments, such as Pinus nigra Arnold or Pinus pinea $\mathrm{L}$., have very scarce regeneration after fires and depend exclusively on the ability of reproductive adults to survive and generate subsequent cohorts. The persistence of such populations depends on the recruitment once adults are able to produce new seeds between fires (Retana et al. 2002; Rodrigo et al. 2007). Post-fire studies in pine forests have focused mainly on early regeneration processes or understory vegetation dynamics, whereas long-term changes in regeneration capacity and their implications for population stability have received less attention (Johnstone et al. 2004; Kazanis and Arianoutsou 2004; Lecomte et al. 2005; González-Tagle et al. 2008).

The Canary Island pine (Pinus canariensis Sweet ex Spreng.) is a palaeoendemic species phylogenetically close to Mediterranean pines (Wang et al. 1999). It is well adapted to forest fires, although it is not clear whether its regeneration depends on the occurrence of forest fires. This species combines serotinous and non-serotinous cones, moreover, adults have an extraordinary sprouting capacity after fire, resulting in a mixture of stand resilience and individual resistance strategies (Climent et al. 2004). The importance of serotinous cones in this species is lower compared with other Mediterranean obligate seeder pines adapted to fire-prone environments, like P. halepensis (less than $40 \%$ vs. between 50 and $100 \%$ of serotinous cones in $P$. canariensis and P. halepensis, respectively) (Climent et al. 2004; Nathan et al. 1999). Therefore, serotiny in Canarian pines could be related not just to forest fires but also to adaptation to dry conditions. Abundant seed rain has also been detected in P. canariensis in the absence of fires (Garcia-del-Rey et al. 2011), but the dynamics of seed rain, regardless of the cone type involved, has never been studied. Previous studies of Canarian pine forests have focused on post-fire regeneration and the influence of stand conditions at early stages (Höllermann 2000; Arévalo et al. 2001; Peters et al. 2001; Climent et al. 2004; Otto et al. 2010); however, long-term studies of successive regeneration have not been carried out.
We present the first study quantifying long-term post-fire regeneration in $P$. canariensis. The aim of this work is to determine if $P$. canariensis can produce functional regeneration regardless of fire by measuring seed rain, fieldgermination rate, mortality and turnover. We also measure the temporal dynamics of these processes and evaluate the effect of biotic and abiotic variables. Our hypothesis is that in natural forests of $P$. canariensis, regeneration is independent of the time elapsed after fire and is influenced mainly by environmental factors.

\section{Methods}

\subsection{Study site}

This study was carried out on the island of La Palma (708 km², 2423 m a.s.l.; Canary Islands, Spain), where $69 \%$ of the forested surface of the island is covered by pine forest (ca. 23,600 ha). This represents almost $40 \%$ of the total surface area of natural pine forests in the Canary Islands archipelago (Pérez de Paz et al. 1994). La Palma is the second island most affected by forest fires in the archipelago, with 12,595 ha burned between 1983 and 2008 (18\% of the island's surface) out of a total of 52,345 ha burned in the archipelago during the same period ( $89 \%$ of the natural pine forest of the Canaries) (Gobierno de Canarias 2011). Consequently, the island of La Palma host the only natural pine forests in the Canaries where it is possible to find a chronological succession of burned areas that have not undergone subsequent fires enabling the study of Canarian pine postfire regeneration on the long term.

Mean annual temperature in the distribution area of pine forest in La Palma varies between 12.5 and $16{ }^{\circ} \mathrm{C}$, while rainfall ranges between 600 and $1000 \mathrm{~mm}$. Forest soils are of volcanic origin, with leptosols, vertisols and andosols as the prevailing types (IUSS Working Group 2006).

\subsection{Experimental design}

A fire chronosequence was established consisting of six forest stands burned 2, 7, 9, 13 and 17 years before the beginning of the study (referred to as fire ages) and an unburned control stand (not burned for at least the last 50 years) (Fig. 1). All stands were typically dry pine forest (del Arco et al. 2006). Although the use of chronosequence has some disadvantages (possible pseudo-replication and differences between study plots relative to historical use or microclimate), the chronosequence have proven to be a suitable method in the study of ecological succession (Bermudez et al 2006; Trabaud 2000). Wildfires included in the chronosequence burned more than 20 ha, and none of the zones were affected by later fires 
Fig. 1 Study sites on La Palma Island (Canary Island, Spain). Plots comprises a chronosequence of five forest fire ages $(2,7,9,13,17$ years after forest fire) and an unburned area (at least 50 years with no fires) located in pine forest. In grey, distribution of the pine forest on the island. Dark grey pure (dry) pine; medium grey with horizontal lines humid pine; light grey pine plantations (Del Arco et al. 2006). All the plots are located in pure (dry) pine forest
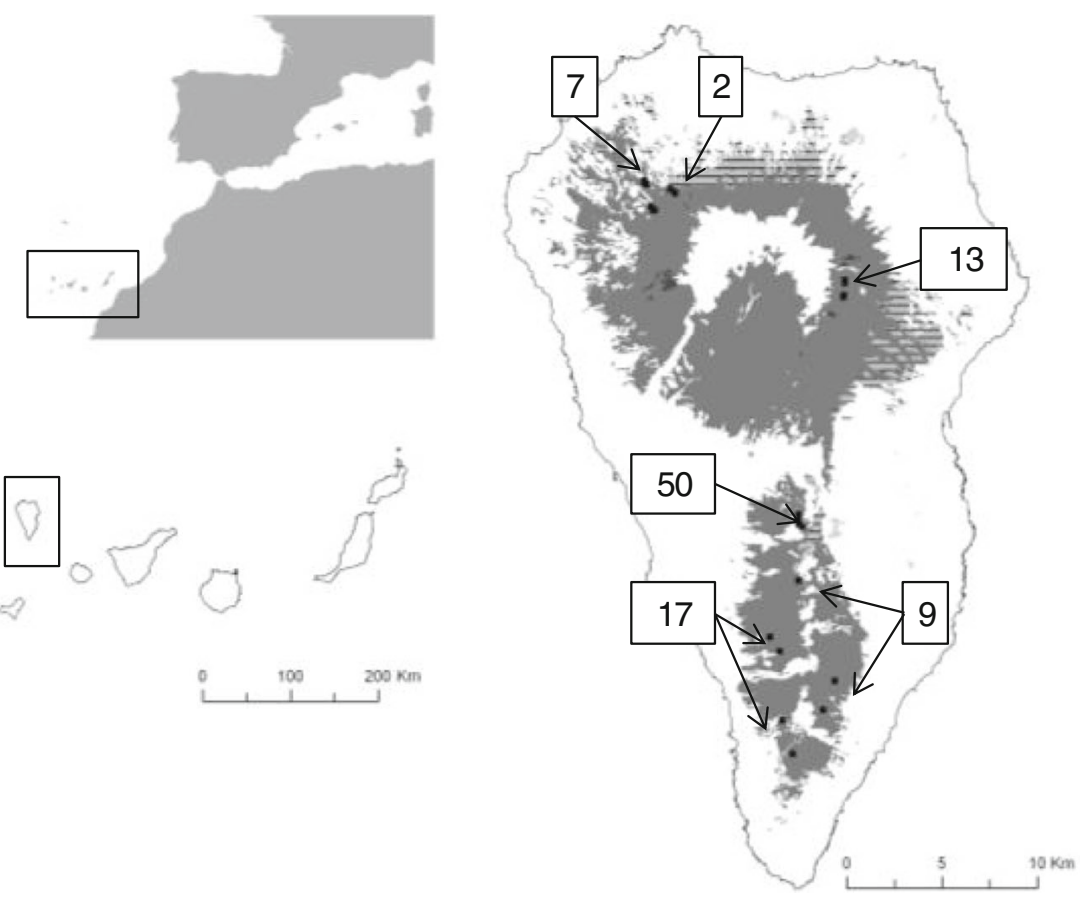

nor subjected to silvicultural treatment (Pérez de Paz et al. 1994).

Four $25 \times 25 \mathrm{~m}$ plots were randomly established in every stand, except for those with 2- and 9-year-old fires, where, in order to avoid pseudo-replication, only three plots were established due to their smaller burned areas. Altitude, aspect, slope and canopy cover were measured in each plot. The number of living adult pine trees and their diameters at breast height (DBH) were also recorded. Only those trees with over $40 \mathrm{~cm}$ of DBH were considered. Canopy height was expressed as the average height of the five trees with the largest DBH in the plot. Litter depth and weight were measured at five $1 \times 1 \mathrm{~m}$ random points in each plot. Data were taken four times a year during the study. In each point, litter layer was removed and weighted in the field. A 200-g subsample was dried to constant weight in order to obtain dry weight in tons per hectare. Mean annual precipitation data were obtained from meteorological stations managed by the Spanish Agency of Meteorology (Appendix). Soil nutrients ( $\mathrm{mg} / \mathrm{kg}$ soil) were taken from the study of Durán et al. (2008) carried out in the same plots of this chronosequence.

Five seed traps of $0.2 \mathrm{~m}^{2}$ and three subplots (for seedling monitoring) of $25 \mathrm{~m}^{2}(5 \times 5 \mathrm{~m})$ were randomly placed in each plot (Otto et al. 2012). Monitoring of the trapped seeds and new germinated seedlings was performed every 3 months. The seedlings already present and new ones found in each survey were recorded, mapped and tagged in the subplots. To ensure that mean values contained the natural interannual variability, we collected data from September 2005 to February 2007, except in 2-year-old plots, which were monitored until August 2008 to complete two full years of study.
For each stand, mean annual values of seed rain, germination, field-germination rate (percentage of germinated seedlings per number of fallen seeds) and mortality were calculated by averaging the data of the subplots and traps for seeds for each year. Turnover was calculated using Eq. 1:

Turnover $=\frac{\text { Germination }- \text { Mortality }}{\text { Germination }+ \text { Mortality }}$

Turnover shows values from 0 to +1 when the population is growing (high germination), and values from 0 to -1 when the population is decreasing (high mortality). Values equal to zero indicate population stability.

\section{Data analysis}

Differences among fire ages for each regeneration parameter were tested using a permutational ANOVA analysis (PERMANOVA). PERMANOVA is a procedure for testing the simultaneous response of one or more variables to one or more factors in an analysis of variance (ANOVA) in an experimental design based on resemblances between measures using permutation methods (Anderson et al. 2008). In our design, fire age and year of monitoring were used as fixed factors, and plots as nested ones. The resemblance matrix required for the analysis was based on Euclidean distance for each regeneration parameter. Significant terms and interactions were investigated using posteriori pair-wise comparisons with the PERMANOVA $t$ statistic. A maximum of 9999 permutations were used to obtain the $p$ values $(p<0.05)$ in 
each dataset, and the Monte Carlo correction was applied where necessary.

To test the relationship between regeneration parameters and environmental variables (Appendix), we used the distance-based linear models (DistLM) procedure. This procedure performs a distance-based analysis on a linear model to obtain a resemblance matrix of each regeneration parameter and predictor variables (Anderson et al. 2008). Environmental variables were normalised to make comparisons. It is then possible to derive meaningful distances between samples, using Euclidean distances. The step-wise procedure was used to add or subtract variables from the model. Akaike's information criterion with second-order correction (AICc) was used to obtain the best model with the smallest number of predictor variables. This modification of the AIC is appropriate when the number of samples is small relative to the number of predictor variables. Marginal tests of environmental variables relationships with each regeneration parameter were performed. Primer 6 and PERMANOVA+ (PRIMER-E Ltd., Plymouth, UK) were used to perform all statistical procedures.

\section{Results}

We collected 1231 seeds with an average of $7.44( \pm 8.08$ standard deviation (SD)) seeds $\mathrm{m}^{-2}$ year ${ }^{-1}$. The number of collected seeds changed significantly among fire ages (pseudo- $F=$ $7.051 ; p=0.004)$. Moreover, seed rain was the only parameter that showed significant interaction between fire age and year of monitoring when the latter was considered as a fixed factor (pseudo- $F=2.441 ; p=0.021$ ), implying that the differences among ages were not consistent throughout the years of monitoring (Table 1). Pair-wise tests showed that higher values of seed rain occurred 13 years after fire (Fig. 2a). By year, seed rain was highest at ages 9 and 13 in 2005. In 2006, the highest values appeared at age 13; whereas in 2007, ages 2 and 17 had the lowest seed rain. On comparing seasonality, despite seed

Table 1 Annual seed rain per age $\left(\right.$ seed $\left.\mathrm{m}^{-2}\right)$ of Pinus canariensis

\begin{tabular}{lcccc}
\hline Age & 2005 & 2006 & 2007 & Average \\
\hline 2 & & $3.47 \mathrm{~b}$ & $2.07 \mathrm{~b}$ & 2.77 \\
7 & $1.27 \mathrm{~b}$ & $0.86 \mathrm{~b}$ & $8.37 \mathrm{ab}$ & 3.50 \\
9 & $14.55 \mathrm{ab}$ & $2.43 \mathrm{~b}$ & $7.51 \mathrm{ab}$ & 8.16 \\
13 & $33.87 \mathrm{a}$ & $23.24 \mathrm{a}$ & $12.87 \mathrm{a}$ & 23.33 \\
17 & $0.80 \mathrm{~b}$ & $3.07 \mathrm{~b}$ & $1.44 \mathrm{~b}$ & 1.77 \\
50 & $4.58 \mathrm{~b}$ & $2.55 \mathrm{~b}$ & $8.57 \mathrm{ab}$ & 5.23 \\
& 11.02 & 5.94 & 6.81 & 7.44 \\
\hline
\end{tabular}

Seed rain at age 2 started to be monitored in February 2006. Letters indicate similar annual seed rain after pair-wise permutational comparison between fire ages $(p<0.05)$ rain occurring throughout the year, it was significantly higher during summer and lower in winter for all fire ages (pseudo$F=8.116 ; p=0.000$ ) (Fig. 3a).

We recorded the germination of 5193 pine seedlings. Mean germination value was $0.34( \pm 0.21 \mathrm{SD})$ seedlings $\mathrm{m}^{-2}$ year ${ }^{-1}$, showing no significant differences among fire ages (pseudo- $F=0.596 ; p=0.736$ ) (Fig. 2b) and no interaction between fire age and monitoring year. However, significant seasonal differences were found, with maximum germination occurring in autumn and winter, whereas minimum values appeared in summer in all fire ages (pseudo$F=10.614 ; p=0.000$ ) (Fig. 3b). Mean germination rate (defined as percentage of new seedlings/number of fallen seeds) was $7.63 \%( \pm 11.27 \mathrm{SD})$, with no significant differences among fire ages (pseudo- $F=0.553 ; p=0.811$ ) (Fig. $2 c$ ). Seasonally, germination rate was significantly higher on winter and lower on summer (pseudo- $F=15.108 ; p=0.000$ ) (Fig. 3c).

The dead seedlings detected were 3146 with an average of $0.13( \pm 0.15 \mathrm{SD})$ seedlings $\mathrm{m}^{-2}$ year $^{-1}$. Significant differences were found among fire ages (pseudo- $F=4.166 ; p=$ 0.021 ) (Fig. 2d) with age 13 recording the highest number of dead seedlings. Seasonal differences were also found with higher values in spring (pseudo- $F=4.054 ; p=0.011$ ) (Fig. 3d).

Seedling density was significantly different among ages (pseudo- $F=10.086 ; p=0.003$ ), with an average of 1.01 ( $\pm 0.85 \mathrm{SD})$ seedlings $\mathrm{m}^{-2}$ year $^{-1}$. Age 13 shows the highest seedling density, while age 2 the lowest (Fig. 2e). Among seasons, autumn-winter had the highest density (pseudo- $F=$ 3.314; $p=0.026$ ) (Fig. 3e). Turnover (Eq. 1) showed no differences for fire ages (pseudo- $F=0.29423 ; p=0.9434$ ) (Fig. 2f) but a marked seasonality throughout the year (pseudo- $F=161.06 ; p=0.000$ ) with negative values in the dry season (prevalence of mortality) and positive values in the rainy season (prevalence of germination) (Fig. 3f).

When analysing the relationship between environmental and regeneration parameters, seed rain, seed germination, seedling mortality and density can be partially explained by the environmental variables measured, while germination rate and turnover cannot. Fire age had no significant relationship with $P$. canariensis regeneration parameters. Nevertheless, the stand elevation, precipitation, canopy cover, density of adults of DBH higher than $40 \mathrm{~cm}$, average DBH of the plot, and soil available nitrogen had significant influence (Table 2).

Seed rain was influenced by elevation, large adults' density, mean annual precipitation and DBH. Distance linear model including the first two variables explain $67.2 \%$ of total variation (Fig. 4a). Soil available nitrogen and average DBH were related to seed germination, explaining $46.83 \%$ of variation (Fig. 4b). As for seedling mortality, $38.3 \%$ of variation was explained by average DBH and elevation (Fig. 4c). 

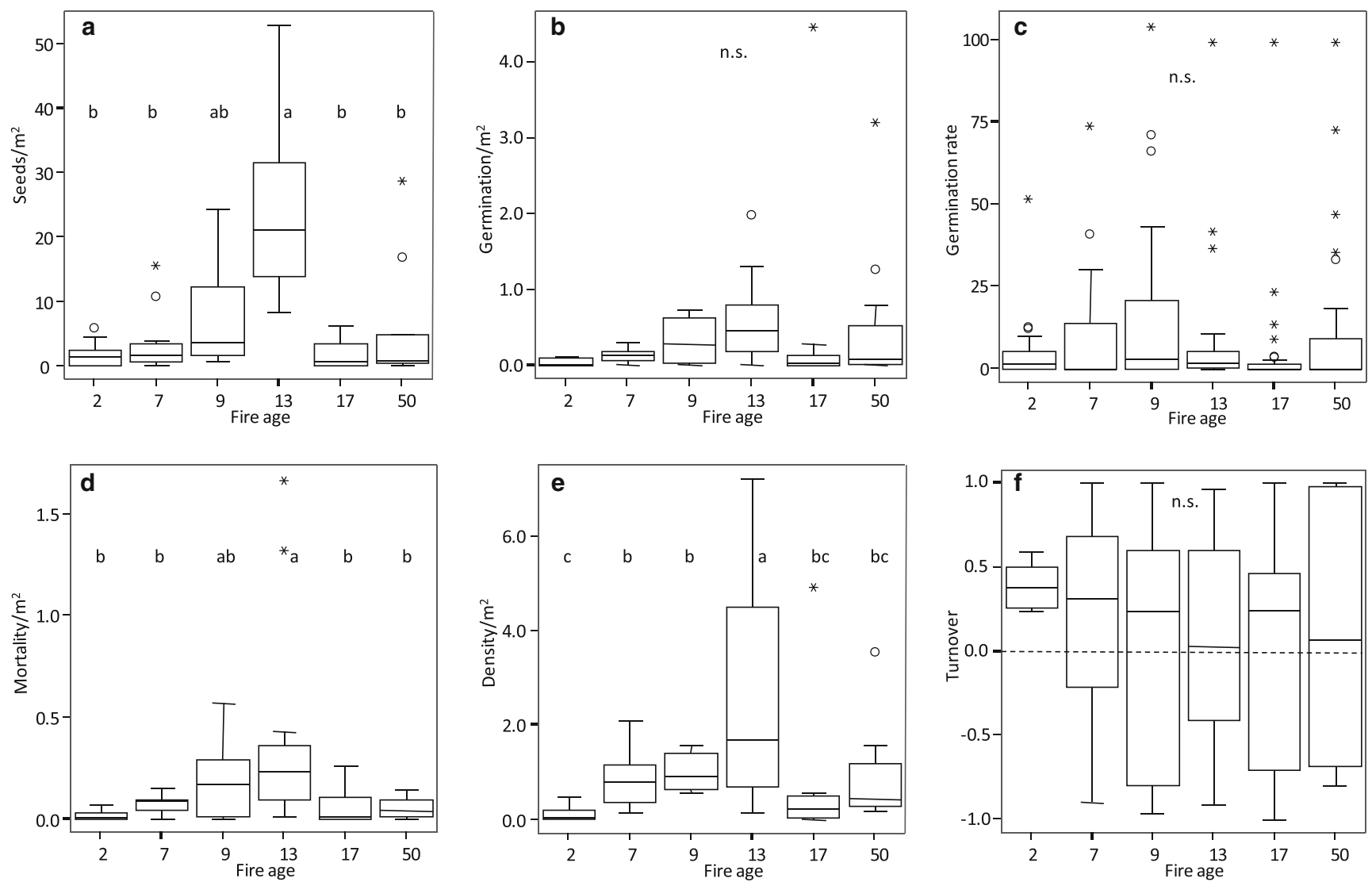

Fig. 2 Average parameters per fire age: a seed rain, $\mathbf{b}$ seed germination, $\mathbf{c}$ germination rate, $\mathbf{d}$ seedling mortality, e seedling density and $\mathbf{f}$ seedling turnover. Seed rain, germination, mortality, and density are expressed as seed or seedling per square metre and year. Germination rate is expressed as percentage of number of new seedling/numbers of seeds, and turnover

\section{Discussion}

Although seed production differed significantly among fire ages, it did not follow any trend regarding time elapsed after fire. Moreover, differences were evident only in certain years, indicating that seed rain production is not affected by fire age but very likely varies depending on environmental characteristics. The number of large (high diameter) adults with the capacity to produce large numbers of seeds together with elevation and precipitation appear to be the most influential variables. In natural pine forests of Tenerife, tree density was also an essential factor conditioning seed availability (Otto et al. 2010). Other pine species, such as $P$. pinea, produce a larger number of seeds in stands with higher numbers of large adults, which in turn are favoured by high precipitation (Calama and Montero 2007). Directly related to tree size is tree age, which has also been recognised as a key factor determining seed production in the obligate seeder P. halepensis (Tapias et al. 2001). Other aspects which could have a role in controlling cone and seed production such as genetic factors or predation have not yet been studied in $P$. canariensis. is defined in Eq. 1. Boxes shows quartiles 1 to 3, the centre lines represent the median and intervals indicate the range of $95 \%$ of cases. Circles represent outliers and asterisks extreme values. Similar letters indicate no significant differences according pair-wise PERMANOVA test $(p<0.05)$ with 9999 permutations

In our study, seeds of $P$. canariensis were released all year round, although the number peaked during summer due to cone opening caused by warm temperatures, and is therefore higher in warmer years. This cone opening has also been detected in warm and dry periods at any time of the year (García-del-Rey et al. 2011). In our field research, germination rate from released seeds was 2$18 \%$, a much lower value compared with germination rates measured under laboratory conditions (20-80\%) (Escudero et al. 2002; Calvo et al 2013). However, this is a typical value for species with recalcitrant seeds in field conditions, which are viable only the first months after release, as is the case for P. halepensis (Daskalakou and Thanos 1996).

We do not know the proportion of serotinous and nonserotinous cones in the studied plots, thus we cannot determine the contribution of each cone type to seed rain. In non-serotinous Mediterranean pines ( $P$. pinea and P. nigra), seed dispersion occurs mainly in late winter and early spring and/or in masting years, while serotinous pines (P. halepensis and Pinus pinaster Aiton) release their seeds in sporadic episodes of dry weather or masting years 

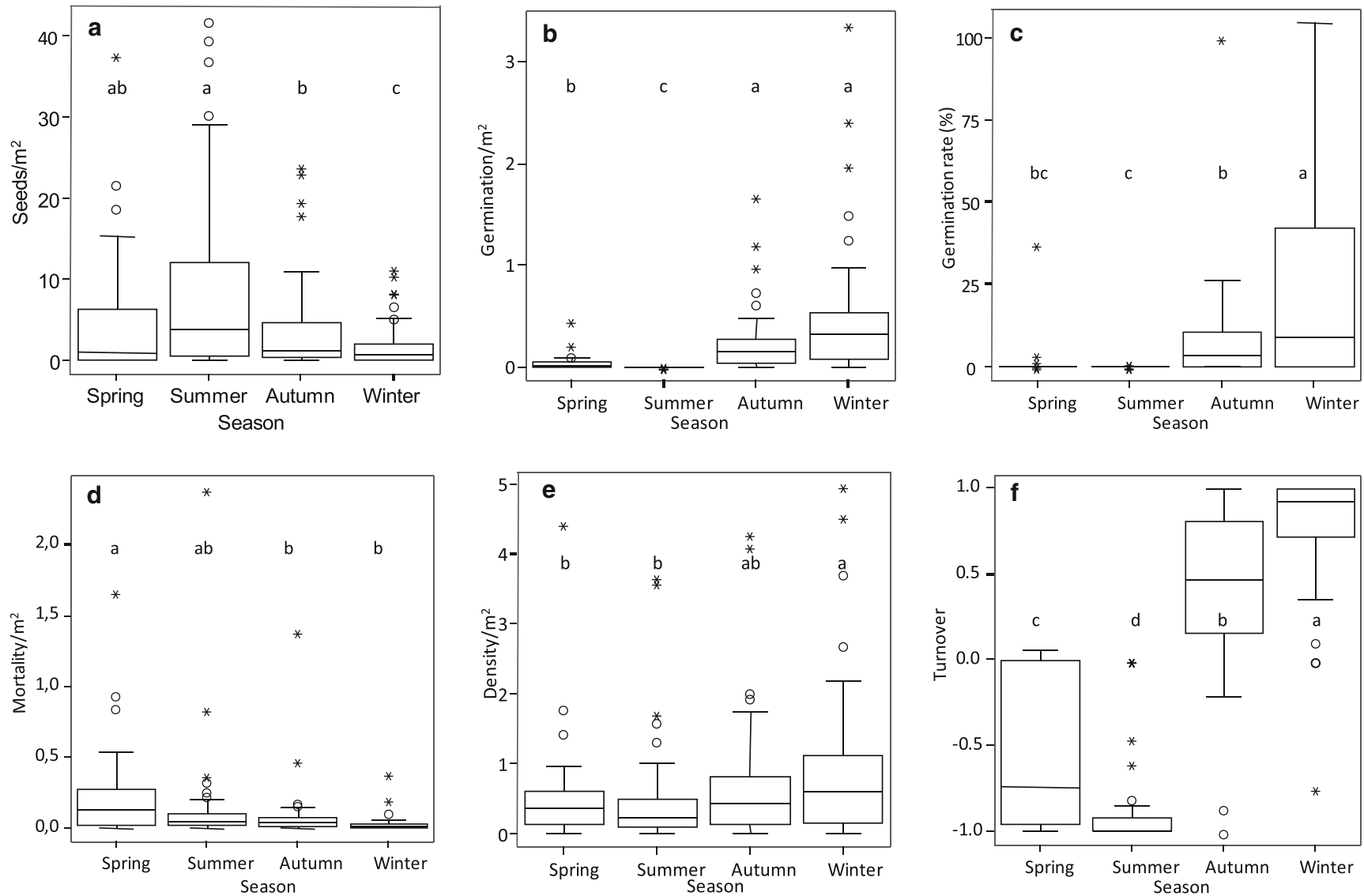

Fig. 3 Seasonal average regeneration parameters of Pinus canariensis (seedlings $\mathrm{m}^{-2}$ ): a seed rain, b germination, $\mathbf{c}$ germination rate, $\mathbf{d}$ mortality, e density and $\mathbf{f}$ turnover (Eq. 1). Boxes show quartiles 1 to 3 , centre lines represent the median and intervals indicate the range of $95 \%$

of cases. Circles represent outliers and asterisk extreme values. Similar letters indicates no significant differences according pair-wise PERM ANOVA test $(p<0.05)$ with 9999 permutations

Table 2 Results of marginal test of relationship between regeneration parameters and environmental variables

\begin{tabular}{|c|c|c|c|c|c|c|c|c|c|c|c|c|}
\hline \multirow[t]{2}{*}{ Variable } & \multicolumn{2}{|l|}{ Seed } & \multicolumn{2}{|c|}{ Germination } & \multicolumn{2}{|l|}{ Mortality } & \multicolumn{2}{|c|}{ Germination rate } & \multicolumn{2}{|l|}{ Density } & \multicolumn{2}{|l|}{ Turnover } \\
\hline & Pseudo- $F$ & $p$ & Pseudo- $F$ & $p$ & Pseudo- $F$ & $p$ & Pseudo- $F$ & $p$ & Pseudo- $F$ & $p$ & Pseudo- $F$ & $p$ \\
\hline Fire age & 0.151 & 0.706 & 1.858 & 0.194 & 0.170 & 0.697 & 0.001 & 0.967 & 0.053 & 0.807 & 0.282 & 0.597 \\
\hline Elevation & 19.956 & $0.001 *$ & 0.554 & 0.448 & 5.807 & $0.023^{*}$ & 0.046 & 0.814 & 2.672 & 0.096 & 3.492 & 0.066 \\
\hline Precipitation & 13.275 & $0.003 *$ & 0.983 & 0.334 & 3.195 & 0.105 & 0.373 & 0.564 & 3.119 & 0.092 & 1.464 & 0.247 \\
\hline Slope & 0.083 & 0.764 & 0.493 & 0.484 & 1.435 & 0.237 & 0.780 & 0.389 & 1.607 & 0.225 & 0.821 & 0.344 \\
\hline Canopy cover & 0.138 & 0.713 & 0.899 & 0.369 & 1.684 & 0.202 & 1.405 & 0.261 & 6.890 & $0.017 *$ & 1.845 & 0.202 \\
\hline Canopy height & 2.127 & 0.142 & 2.717 & 0.124 & 2.864 & 0.118 & 0.020 & 0.886 & 1.411 & 0.253 & 1.818 & 0.208 \\
\hline Adult density & 14.024 & $0.001 *$ & 3.432 & 0.079 & 2.127 & 0.173 & 0.016 & 0.896 & 1.036 & 0.367 & 2.317 & 0.132 \\
\hline DBH & 5.191 & $0.020^{*}$ & 5.420 & $0.030^{*}$ & 7.840 & $0.004 *$ & 0.859 & 0.356 & 5.936 & $0.026^{*}$ & 3.211 & 0.078 \\
\hline Basal area & 1.008 & 0.343 & 0.015 & 0.903 & 0.069 & 0.778 & 1.220 & 0.275 & 0.102 & 0.739 & 2.587 & 0.132 \\
\hline Litter depth & 2.921 & 0.098 & 0.096 & 0.762 & 0.000 & 0.985 & 0.035 & 0.838 & 0.022 & 0.887 & 0.726 & 0.414 \\
\hline Litter weight & 3.072 & 0.107 & 0.000 & 0.986 & 0.313 & 0.568 & 0.004 & 0.949 & 0.407 & 0.509 & 0.011 & 0.922 \\
\hline $\mathrm{N}$ avalaible & 0.881 & 0.380 & 7.200 & $0.018^{*}$ & 0.406 & 0.489 & 0.117 & 0.744 & 2.087 & 0.152 & 0.083 & 0.782 \\
\hline $\mathrm{P}$ available & 0.933 & 0.329 & 3.472 & 0.083 & 0.507 & 0.474 & 0.883 & 0.387 & 1.508 & 0.247 & 1.923 & 0.167 \\
\hline
\end{tabular}

${ }^{*} p<0.05$, significant relationships 

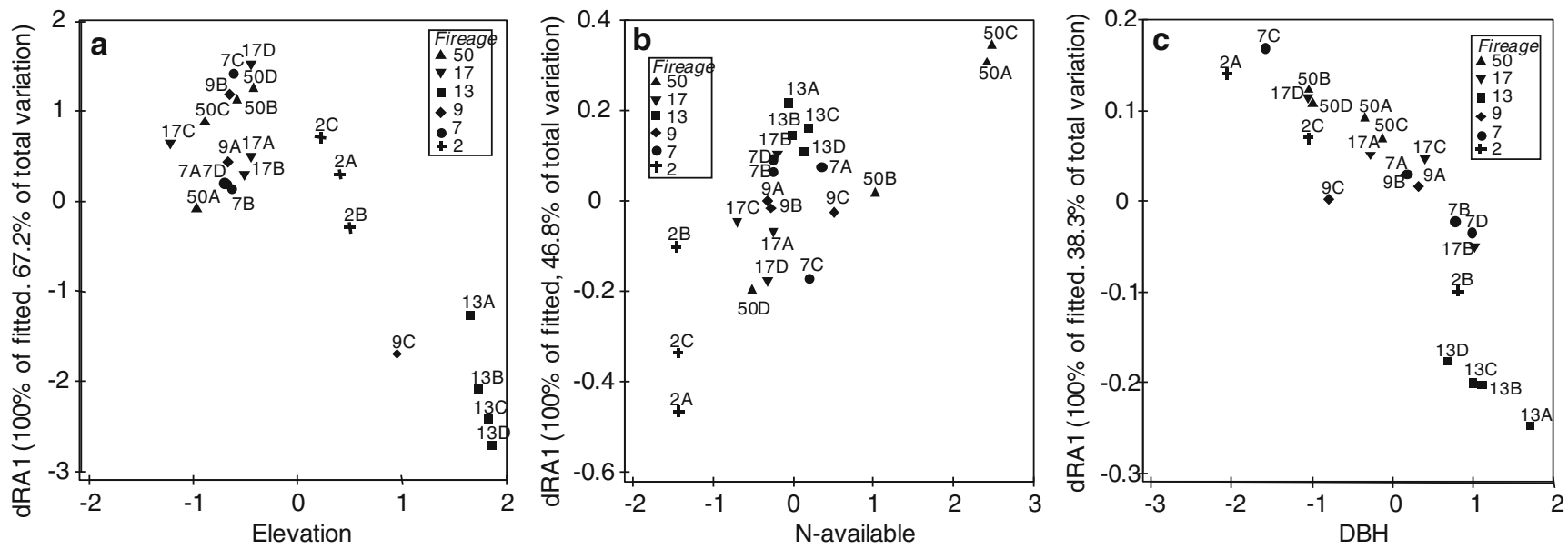

Fig. 4 Distance-based redundancy analysis (dbRDA) plots using the best set of predictor variables. a Seed rain, $\mathbf{b}$ germination and $\mathbf{c}$ mortality. Euclidean distance resemblance matrix was used

(Daskalakou and Thanos 1996; Skordilis and Thanos 1997; Tapias et al. 2001). The release of Aleppo pine seeds during dry weather events (also called weak serotiny or xeriscence) is considered an advantage for the establishment in an ecological scenario where potential competitors have been suppressed (Espelta et al. 2011; Nathan et al. 1999). This gives an idea of the behaviour of $P$. canariensis, in which both serotinous and non-serotinous cones combine to produce seed rain over the whole year. This continuous supply of seeds allows a transient seed bank throughout the year, offsetting the problem of rapid loss of seed viability on the ground, which is typical of many pine species on field conditions (Keeley and Zedler 1998). Additionally, seeds can be wind dispersed over distances of $1.6 \mathrm{~km}$, allowing low-productive stands to receive seed inputs from near high-productive stands (López de Heredia et al. 2010). As a result of this pattern, Canarian pine forests always appear to have available seeds, both in the canopy and on the ground, able to germinate at any time of the year.

In contrast to seed production, no significant differences were detected in seed germination among fire ages. From the set of environmental variables measured, average adult diameter and soil nitrogen content were the most important. In the same fire chronosequence used in our study, Durán et al. (2008) found that soil nitrogen content is affected by forest fires, showing lower values in burned than unburned stands and suggested that these differences could cause long-term reductions in productivity. If so, very frequent fires could prevent recovery of nutrients available in the soil, and, consequently, affect and hinder seed germination, as well as altering its spatial distribution. Correlation with this modification of nitrogen content could be established only at extreme fire ages ( 2 and 50 years after fire), with the germination trend being lowest in the younger age group ( 2 years after fire) and highest in the older one (50 years). However, intermediate ages showed no relation to fire age. In fact, age 13 displayed even higher germination values than control areas. The recovery of nitrogen content in the long term may be masked or exceeded in importance by other stand conditions such as the modification of nutrients spatial heterogeneity (Rodríguez et al. 2009). Consequently, the existence of suitable microsites for germination and recruitment seems crucial for $P$. canariensis regeneration, as shown in other pine species (de Groot et al. 2004; Bonnet et al. 2005; Vega et al. 2008). Thus, fertilisation experiments on seeds of $P$. canariensis would be required to test the influence of nutrient soil content on germination rates.

Seedling mortality differed significantly among fire ages, but was unrelated to time elapsed after fire. Again, stand characteristics seem to be responsible for seedling mortality; however, the low variability explained by our model, including elevation and diameter of adults as the most important variables, point to the influence of other variables not considered here. Higher rates of mortality are concentrated in the dry season most likely due to water stress (Luis et al. 2001). It has also been shown that different tree species seedlings show higher mortality when subjected simultaneously to shade and drought conditions (Sack 2004). Additionally, Canarian pine seedlings show limitations in their development under these conditions, affecting their survival (Climent et al. 2006). Despite favouring seed production, high adult density can produce adverse conditions for regeneration by reducing light in the understory, or by competing for water and nutrients, thus increasing seedling mortality, as has already been shown for P. canariensis (Arévalo and Fernández-Palacios 2008; Peters et al. 2001).

Few studies that simultaneously consider the four regeneration processes (seed rain, seedling germination, 
mortality and density) can be found in the literature (Miller and Cummins 1982; Boydak 2004; Neeman et al. 2004). This is the first study carried out on $P$. canariensis including all of them, giving a more complete picture of the dynamics of its forest regeneration. Previous studies on this ecosystem found how regeneration in the absence of fire is notable, but these only focused on a single parameter: seedling germination (Arévalo et al. 2001, 2005; Arévalo and FernándezPalacios 2005, 2008; Otto et al. 2010). Despite of the high environmental variability found on the island of La Palma and the risk of inherent pseudo-replication in the establishment of a chronosequence, we expected fire to be the main factor controlling regeneration parameters overriding the possible effects of environmental variability; however, our results show that stand characteristics are more important.

From our results, a seasonal pattern of Canary Island pine regeneration can be drawn, although some variability exists among stands. A substantial summer seed release is followed by germination during the rainy season (autumnwinter), until the next dry season when most of the germinated seedlings die mainly due to water stress. Intraspecific competition may also possibly appear among surviving seedlings. Occasionally, introduced herbivores, mainly European rabbits, can feed on seedlings; however, this effect was rarely observed in our study. Although seedling density fluctuates during the year, the continuous supply of seeds and seasonal turnover allows the existence of a permanent seedling bank, which ensures stable, mature populations of $P$. canariensis. The regeneration dynamic pattern shown by $P$. canariensis combines a mixture of fire tolerant and fire embracer Mediterranean pine regeneration strategies (Keeley 2012).

The continuously renewed seedling bank and the presence of long distance seeds dispersal allow this species to maintain stable populations. These features also allow it to act as a pioneer species exploiting new opportunities to establish after disturbances, such as forest fires or canopy gaps created by storms or dead adult trees. This ability is especially useful in volcanic territories allowing the rapid colonisation of new areas originating from lava flows, which is indeed the case for the Canary Islands. Accordingly, Canarian pine stands described in some works as having high tree density but low regeneration might actually be young populations replacing old ones damaged by past disturbances (Höllermann 2000; Climent et al. 2004).

Although P. canariensis seems to tolerate the current fire regime, it is uncertain how fire regime changes will affect its regeneration in the future. Charcoal palaeorecords reveal how fire regimes have been modified since humans first arrived on the Canary Islands (de Nascimento et al. 2009; Nogué et al. 2013). At present, forest fire frequency has significantly increased over the last few decades in the Mediterranean region (Camia et al. 2008). This scenario is also shared by the Canary Islands, and in $\mathrm{La}$ Palma, the number of fires has increased by $50 \%$ compared with previous decades (Gobierno de Canarias 2011). Predictions about climate warming in the Mediterranean region suggest an increase in air temperature and a reduction in summer rainfall, consequently, forest fire frequency is expected to increase significantly (Stocks et al. 1998; Flannigan et al. 2000; Gillet et al. 2004). Changes in fire regimes have been confirmed as affecting growth and reproductive traits of fire-adapted pine species as P. halepensis (Eugenio et al. 2006) and other Mediterranean species not so adapted to fire, such as $P$. pinea and Pinus sylvestris L. (Pausas 2004). Similar changes in fire regime or intensities may have unexpected effects on regeneration and related ecological processes in $P$. canariensis. In this context, the need to maintain longterm monitoring is clear, as a basic part of the correct management of Canarian pine forests.

\section{Conclusions}

We conclude that fire has little effect on long-term regeneration of $P$. canariensis in natural forests of La Palma, although a negative impact has been detected on early post-fire regeneration. Between 2 to 7 years after fire, regeneration dynamics are controlled primarily by stand conditions such as elevation, number of seed producer trees and density of adults. However, there are still some unknown aspects of the regeneration of this species, where the recurrence of fire can play an important role, as for example, in the pattern of seedling survival or the occurrence of intra or inter-specific competition in the seedling bank. The studied chronosequence offers an excellent opportunity for such studies. Data obtained in the future and the results presented here are of great interest because they provide novel information regarding reference conditions for Canarian pine forests, especially considering that pine forests in La Palma are natural and have mainly been subjected to low intensity of use and management.

Acknowledgments We are grateful to Félix Medina and the personnel of the Unidad Insular de Medio Ambiente for field assistance, and all volunteers who helped us in the field work. We especially thank Jorge Durán and Alexandra Rodríguez for their generosity lending us their data and Silvia Fernández for her statistical advice. We also thank Kostas Triantis for his suggestions on the drafting of this paper.

Funding This work was partially funded through the project CGL2006-13665-C02-02/BOS of the Ministerio de Ciencia y Tecnología and the Cabildo de La Palma. 


\section{Appendix}

Table 3 Biotic and abiotic characteristics of the permanent plots (mean values)

\begin{tabular}{|c|c|c|c|c|c|c|c|c|c|c|c|c|}
\hline F. age & $\begin{array}{l}\text { Alt. } \\
\text { (m) }\end{array}$ & $\begin{array}{l}\text { G. age. } \\
\text { (kyrs) }\end{array}$ & Or. & Exp. & $\begin{array}{l}\text { Slp. } \\
\left({ }^{\circ}\right)\end{array}$ & $\begin{array}{l}\text { Prec. } \\
(\mathrm{mm})\end{array}$ & $\begin{array}{l}\text { Dens. } \\
(\text { Ind.ha }\end{array}$ & $\begin{array}{l}\text { Dens. }>40 \\
\text { (Ind./ha) }\end{array}$ & $\begin{array}{l}\text { Can. } \\
\text { height } \\
\text { (m) }\end{array}$ & $\begin{array}{l}\text { Can. } \\
\text { cov. } \\
(\%)\end{array}$ & $\begin{array}{l}\mathrm{DBH} \pm \text { std } \\
\text { error }(\mathrm{cm})\end{array}$ & $\begin{array}{l}\text { Basal } \\
\text { area } \\
\left(\mathrm{m}^{2} \mathrm{ha}^{-1}\right)\end{array}$ \\
\hline $2-1$ & 1509 & $400-800$ & NWNW & ww & 30 & 800 & 576 & 48 & 5.6 & 31 & $46.6 \pm 12.0$ & 12.2 \\
\hline $2-2$ & 1535 & $400-800$ & NW & ww & 21 & 800 & 112 & 80 & 16.2 & 29 & $45.4 \pm 13.9$ & 19.6 \\
\hline $2-3$ & 1457 & $400-800$ & NW & ww & 23 & 800 & 512 & 32 & 12.5 & 15 & $29.0 \pm 11.3$ & 24.4 \\
\hline $7-1$ & 1208 & $400-800$ & NW & ww & 9 & 660 & 272 & 112 & 18.7 & 53 & $38.4 \pm 10.1$ & 32.1 \\
\hline $7-2$ & 1224 & $400-800$ & $\mathrm{NE}$ & ww & 21 & 660 & 160 & 112 & 20.3 & 56 & $44.9 \pm 10.6$ & 26.6 \\
\hline $7-3$ & 1226 & $400-800$ & NW & ww & 4 & 660 & 640 & 32 & 9.4 & 39 & $48.7 \pm 38.3$ & 27.3 \\
\hline $7-4$ & 1204 & $400-800$ & SW & ww & 18 & 660 & 144 & 112 & 19.5 & 55 & $47.6 \pm 9.5$ & 26.5 \\
\hline $9-1$ & 1214 & $20-125$ & $\mathrm{SE}$ & ww & 15 & 730 & 224 & 96 & 15.5 & 70 & $41.2 \pm 16.7$ & 32.2 \\
\hline $9-2$ & 1219 & $20-125$ & $\mathrm{E}$ & ww & 22 & 510 & 128 & 48 & 16.9 & 64 & $50.1 \pm 25.9$ & 20.1 \\
\hline $9-3$ & 1659 & $20-125$ & SW & lw & 13 & 630 & 1008 & 144 & 15.8 & 68 & $31.1 \pm 9.1$ & 60.2 \\
\hline $13-1$ & 1852 & $400-800$ & $\mathrm{NE}$ & ww & 9 & 1380 & 80 & 80 & 21.2 & 45 & $56.9 \pm 8.6$ & 20.7 \\
\hline $13-2$ & 1874 & $400-800$ & $\mathrm{~N}$ & ww & 15 & 1380 & 144 & 128 & 17.1 & 44 & $49.1 \pm 9.1$ & 28.1 \\
\hline $13-3$ & 1898 & $400-800$ & SE & ww & 8 & 1380 & 192 & 144 & 19.4 & 64 & $47.8 \pm 11.6$ & 36.3 \\
\hline $13-4$ & 1909 & $400-800$ & SE & ww & 20 & 1380 & 272 & 160 & 22.2 & 69 & $43.7 \pm 11.0$ & 43.3 \\
\hline $17-1$ & 1274 & $0.5-20$ & SE & lw & 5 & 720 & 560 & 80 & 19.8 & 69 & $32.9 \pm 7.6$ & 47.1 \\
\hline $17-2$ & 1257 & $0.5-20$ & $\mathrm{~N}$ & lw & 24 & 670 & 112 & 96 & 21.6 & 61 & $48.1 \pm 13.1$ & 21.6 \\
\hline $17-3$ & 1062 & $0.5-20$ & SW & lw & 5 & 420 & 208 & 112 & 20.2 & 69 & $45.7 \pm 8.6$ & 30.1 \\
\hline $17-4$ & 1275 & $0.5-20$ & W & lw & 17 & 720 & 784 & 16 & 14.0 & 52 & $26.9 \pm 5.4$ & 33.7 \\
\hline $50-1$ & 1132 & $0.5-20$ & $\mathrm{~N}$ & lw & 6 & 1050 & 384 & 144 & 14.7 & 63 & $38.0 \pm 11.6$ & 36.5 \\
\hline $50-2$ & 1238 & $0.5-20$ & NW & lw & 30 & 1050 & 496 & 48 & 9.1 & 52 & $34.3 \pm 10.2$ & 25.0 \\
\hline $50-3$ & 1153 & $0.5-20$ & SW & lw & 7 & 1050 & 320 & 80 & 16.5 & 65 & $40.6 \pm 13.1$ & 36.6 \\
\hline $50-4$ & 1282 & $0.5-20$ & SW & lw & 21 & 1050 & 448 & 32 & 12.4 & 43 & $30.5 \pm 6.3$ & 22.0 \\
\hline
\end{tabular}

Rainfall data were obtained from the nearest meteorological station of the Spanish Agency of Meteorology (AEMET)

F. age fire age plot, Alt. altitude (m), G. age geological age (kyr), Or. orientation, Exp. wind exposure (leeward (lw), windward (ww)), Slp. slope (deg), Prec. annual average precipitation (mm), Dens. adult trees density, Dens. $>40$ adult tree density with $D B H>40, D B H$ diameter breast height (cm), Can. height canopy height (m), Can. cov. canopy cover (\%)

\section{References}

Anderson M, Gorley R, Clarke K (2008) Permanova+ for primer: guide to software and statistical methods. Primer-E Ltd., Plymouth

Arévalo JR, Fernández-Palacios JM (2005) From pine plantations to natural stands. Ecological restoration of a Pinus canariensis Sweet, ex Spreng forest. Plant Ecol 181:217-226

Arévalo JR, Fernández-Palacios JM (2008) Natural regeneration of Pinus canariensis Chr. Sm. Ex DC in Buch in forest plantations after thinning. Open For Sci J 1:54-60

Arévalo JR, Fernández-Palacios JM, Jiménez MJ, Gil P (2001) The effect of fire intensity on the understory composition of two Pinus canariensis reforested stands in Tenerife (Canary Islands). For Ecol Manag 148:21-29

Arévalo JR, Naranjo-Cigala A, Pascual MS (2005) Regeneration in a mixed stand of native Pinus canariensis and introduced Pinus pinea species. Acta Oecol 28:87-94
Bermúdez AM, Fernández-Palacios JM, González-Mancebo JM, Patiño J, Árevalo JR, Otto R, Delgado JD (2006) Floristic and structural recovery of a laurel forest community after clear-cutting: a 60 years chronosequence on La Palma (Canary Islands). Ann For Sci 63: 109-119

Bonnet VH, Schoettle AW, Shepperd WD (2005) Postfire environmental conditions influence the spatial pattern of regeneration for Pinus ponderosa. Can J For Res 35:37-47

Boydak M (2004) Silvicultural characteristics and natural regeneration of Pinus brutia Ten.- - a review. Plant Ecol 171:153-163

Calama R, Montero G (2007) Cone and seed production from stone pine (Pinus pinea L.) stands in central range (Spain). Eur J For Res 126:23-35

Calvo L, García-Domínguez C, Naranjo A, Arévalo JR (2013) Effects of light/darkness, thermal shocks and inhibitory components on germination of Pinus canariensis, $P$. halepensis and $P$. pinea. Eur J For Res 132:909-917

Camia A, San-Miguel-Ayanz J, Kucera J, Amatulli G, Boca R, Libertà G, Durrant T, Schmuck G, Schulte E, Bucki M (2008) Forest fires in 
Europe 2007. Office for Official Publications of the European Communities, Luxemburgo

Catovsky S, Bazzaz FA (2002) Nitrogen availability influences regeneration of temperate tree species in the understory seedling bank. Ecol Appl 12:1056-1070

Climent J, Tapias R, Pardos JA, Gil L (2004) Fire adaptations in the Canary Islands pine (Pinus canariensis). Plant Ecol 171:185-196

Climent J, Aranda I, Alonso J, Pardos JA, Gil L (2006) Developmental constraints limit the response of Canary Island pine seedlings to combined shade and drought. For Ecol Manag 231:164-168

Daskalakou EN, Thanos CA (1996) Aleppo Pine (Pinus halepensis) postfire regeneration: the role of canopy and soil seed banks. Int $\mathbf{J}$ Wildland Fire 6:59-66

de Groot WJ, Bothwell PM, Taylor SW, Wotton BM, Stocks BJ, Alexander ME (2004) Jack pine regeneration and crown fires. Can J For Res 34:1634-1641

de Nascimento L, Willis KJ, Fernández-Palacios JM, Criado C, Whittaker RJ (2009) The long-term ecology of the lost forests of La Laguna, Tenerife (Canary Islands). J Biogeogr 36:499-514

del Arco MJ, Wildpret W, Pérez PL, Rodríguez O, Acebes JR, García A, Martin VE, Reyes JA, Salas M, Diaz MA, Bermejo JA, González R, Cabrera MV, García S (2006) Mapa de vegetación de Canarias. GRAFCAN, Santa Cruz de Tenerife

Durán J, Rodríguez A, Fernández-Palacios JM, Gallardo A (2008) Changes in soil $\mathrm{N}$ and $\mathrm{P}$ availability in a Pinus canariensis fire chronosequence. For Ecol Manag 256:384-387

Escudero A, Pérez-García F, Luzuriaga AL (2002) Effects of light, temperature and population variability on the germination of seven Spanish pines. Seed Sci Res 12:261-271

Eshel A, Henig-Sever N, Ne'eman G (2000) Spatial variation of seedling distribution in an East Mediterranean pine woodland at the beginning of post-fire succession. Plant Ecol 148:175-182

Espelta JM, Arnan X, Rodrigo A (2011) Non-fire induced seed release in a weakly serotinous pine: climatic factors, maintenance costs or both? Oikos 120:1752-1760

Eugenio M, Verkaik I, Lloret F, Espelta JM (2006) Recruitment and growth decline in Pinus halepensis populations after recurrent wildfires in Catalonia (NE Iberian Peninsula). For Ecol Manag 231:4754

Fernandes PM, Vega JA, Jimenez E, Rigolot E (2008) Fire resistance of European pines. For Ecol Manag 256:246-255

Flannigan MD, Stocks BJ, Wotton BM (2000) Climate change and forests fires. Sci Total Environ 262:221-229

García-del-Rey E, Nanos N, López-de-Heredia U, Gil P, Otto R, Fernández-Palacios JM, Gil L (2011) Spatiotemporal variation of a Pinus seed rain available for an endemic finch in an insular environment. Eur J Wildl Res 57:337-347

Gillet NP, Weaver AJ, Zwiers FW, Flannigan MD (2004) Detecting the effect of climate change on Canadian forest fires. Geophys Res Lett 31. doi:10.1029/2004GL020876

Gobierno de Canarias (2011) Estadísticas de Incendios de la isla de La Palma desde 1983. http://www.gobiernodecanarias.org/cmayot/ medioambiente/medionatural/forestal/estadisticas/IsladeLaPalma. html. Accessed February 2011

González-Tagle MA, Schwendenmann L, Jiménez Pérez J, Schulz R (2008) Forest structure and woody plant species composition along a fire chronosequence in mixed pine-oak forest in the Sierra Madre Oriental, Northeast Mexico. For Ecol Manag 256:161-167

Höllermann P (2000) The impact of fire in Canarian ecosystems 1983 1998. Erdkunde 54:70-75

IUSS Working Group WRB (2006) World reference base for soil resources 2006. 2nd ed. World soil resources reports No. 103. FAO, Rome

Johnstone JF, Chapin FS III, Foote J, Kemmett S, Price K, Viereck L (2004) Decadal observations of tree regeneration following fire in boreal forests. Can J For Res 34:267-273
Kazanis D, Arianoutsou M (2004) Long-term post-fire vegetation dynamics in Pinus halepensis forests of Central Greece: a functional group approach. Plant Ecol 171:101-121

Keeley JE, Zedler PH (1998) Evolution of life histories in Pinus. In: Richardson DM (ed) Ecology and biogeography of Pinus. Cambridge University Press, Cambridge, pp 219-251

Keeley JE (2012) Ecology and evolution of pine life histories. Ann For Sci 69:445-453

Lecomte N, Simard M, Bergeron Y, Larouche A, Asnong H, Richard PJH (2005) Effects of fire severity and initial tree composition on understorey vegetation dynamics in a boreal landscape inferred from chronosequence and paleoecological data. J Veg Sci 16:665-674

Luis VC, Jiménez MS, Gil P, Morales D (2001) Influencia de los factores ambientales en la mortalidad de plántulas de Pinus canariensis en condiciones naturales. Actas III Congr For Esp 357-362

López de Heredia U, Venturas M, López RA, Gil L (2010) High biogeographical and evolutionary value of Canary Island pine populations out of the elevational pine belt: the case of a relict coastal population. J Biogeogr 37:2371-2383

Miller GR, Cummins RP (1982) Regeneration of Scots pine Pinus sylvestris at a natural tree-line in the Cairngorm Mountains, Scotland. Holarct Ecol 5:27-34

Nathan R, Safriel UN, Noy-Meir I, Schiller G (1999) Seed release without fire in Pinus halepensis, a Mediterranean serotinous wind-dispersed tree. J Ecol 87:659-669

Ne'eman G, Goubitz S, Nathan R (2004) Reproductive traits of Pinus halepensis in the light of fire a critical review. Plant Ecol 171:69-79

Nogué S, de Nascimento L, Fernández-Palacios JM, Whittaker RJ, Willis KJ (2013) The ancient relict forests of La Gomera, Canary Islands, and their sensitivity to environmental change. J Ecol 101:368-377

Otto R, García-del-Rey E, Gil Muñoz P, Fernández-Palacios JM (2010) The effect of fire severity on first-year seedling establishment in a Pinus canariensis forest on Tenerife, Canary Islands. Eur J of For Res 129:499-508

Otto R, García-del-Rey E, Méndez J, Fernández-Palacios JM (2012) Effects of thinning on seed rain, regeneration and understory vegetation in a Pinus canariensis plantation (Tenerife, Canary Islands). For Ecol Manag 280:71-81

Pausas JG (2004) La recurrencia de incendios en el monte mediterráneo. In: Vallejo VR, Alloza JA (eds) Avances en el estudio de la gestión del monte Mediterráneo. Fundación CEAM, Valencia, pp 47-64

Pérez de Paz PL, del Arco Aguilar MJ, Rodríguez Delgado O, Acebes Ginovés JR, Marrero Gómez MV, de la Wildpret Torre W (1994) Atlas cartográfico de los pinares canarios: III. La Palma. Viceconsejería de Medio Ambiente, Santa Cruz de Tenerife

Peters J, Luis V, Jiménez MS, Gil P, Morales D (2001) Influencia de la luz en el crecimiento y mortalidad de plántulas de Pinus canariensis. Actas III Congr For Esp. Junta de Andalucía, Málaga, pp 363-368

Retana J, Espelta JM, Habrouk A, Ordóñez JL, Sola-Morales F (2002) Regeneration patterns of three Mediterranean pines and forest changes after a large wildfire in north-eastern Spain. Ecoscience 9: 89-97

Rodrigo A, Quintan V, Retana J (2007) Fire reduces Pinus pinea distribution in northeast Iberian Peninsula. Ecoscience 14:23-30

Rodríguez A, Durán J, Fernández-Palacios JM, Gallardo A (2009) Wildfire changes the spatial pattern of soil nutrient availability in Pinus canariensis forests. Ann For Sci 66:210. doi:10.1051/forest/ 2008092

Sack L (2004) Responses of temperate woody seedlings to shade and drought: do trade-offs limit potential niche differentiation? Oikos 107:110-127

Skordilis A, Thanos CA (1997) Comparative ecophysiology of seed germination strategies in the seven pine species naturally growing in Greece. In: Ellis RH, Murdoch AI, Hong TD (eds) Basic and applied 
aspects of seed biology. Kluwer Academic Publishers, Dordrecht, pp 623-632

Stocks BJ, Fosberg MA, Lynham TJ, Mearns L, Wotton BM, Yang Q, Jin J-Z, Lawrence K, Hartley GR, Mason JA, Mckenney DW (1998) Climate change and forest fire potential in Russian and Canadian boreal forests. Clim Chang 38:1-13

Tapias R, Gil L, Fuentes-Utrilla P, Pardos JA (2001) Canopy seed banks in Mediterranean pines of south-eastern Spain: a comparison between Pinus halepensis Mill, P. pinaster Ait, P. nigra Arn. and P. pinea L. J Ecol 89:629-638

Trabaud L (2000) Postfire-regeneration of Pinus halepensis forests in the West Mediterranean. In: Ne'eman G, Trabaud L (eds) Ecology, biogeography and management of Pinus halepensis and P. brutia forest ecosystems in the Mediterranean Basin. Backhuys Publishers, Leiden, pp 257-268

Vega JA, Fernández C, Pérez-Gorostiaga P, Fonturbel T (2008) The influence of fire severity, serotiny, and post-fire management on Pinus pinaster Ait. recruitment in three burnt areas in Galicia (NW Spain). For Ecol Manag 256:1596-1603

Wang XR, Tsumura Y, Yoshimaru H, Nagasaka K, Szmidt AE (1999) Phylogenetic relationships of Eurasian pines (Pinus, Pinaceae) based on chloroplast $r b c L$, matK, rpl20-rps 18 spacer, and trnV intron sequences. Am J Bot 86:1742-1753 